
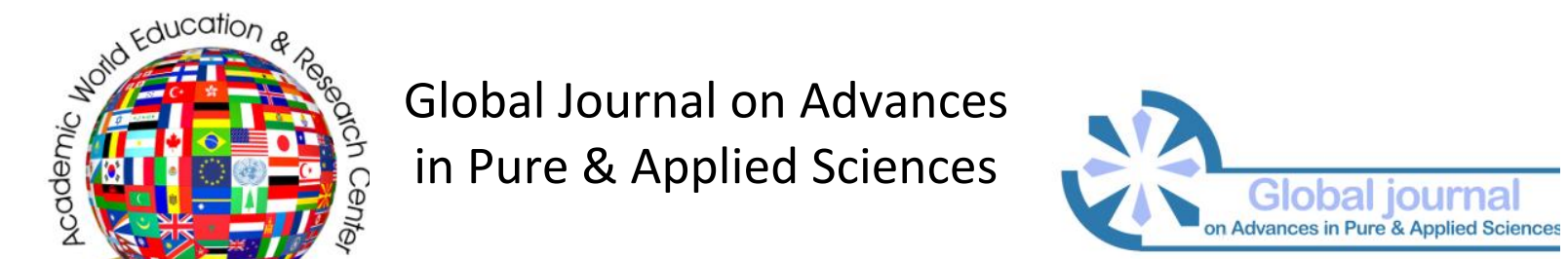

Issue 7 (2016) 175-182

Selected Paper of 2nd World Conference on Health Sciences (H-SCl 2015)

30 April-02 May 2015 Efes Sürmeli Hotel \& Convention Center - Izmir, Kuşadası, Turkey

\title{
Euthanasia: Analysis for the Concept from Islamic Perception
}

Ahmad Hussien Rayan *, Faculty of Nursing, Zarqa University, Jordan.

Abdulkarim Alzayyat, Faculty of Nursing, Al-Ghad International Colleges for Health Sciences, Jordan.

Malek Mohammad Khalil, Faculty of Nursing, Zarqa University, Jordan.

\section{Suggested Citation:}

Rayan, A., H., Alzayyat A. \& Khalil, M., M. (2016). Euthanasia: Analysis for the Concept from Islamic Perception, Global Journal on Advances in Pure \& Applied Sciences. [Online]. 07, pp 175-182. Available from: www.propaas.eu

Received October 10, 2014; revised December 07, 2014; accepted March 03, 2015.

Selection and peer review under responsibility of Prof. Dr. Fahrettin Sadikoglu, Near East University. (C)2016 Academic World Education \& Research Center. All rights reserved.

\begin{abstract}
Euthanasia is ethically, religiously, and legally charged topic. Health care professionals should integrate spiritual aspects in their decision making regarding euthanasia while dealing with muslim patients. The purpose of this paper is to examine the Islami view for the concept of euthanasia and its permissiblility in Islam, while discussing different ethical and legal aspects that may affect the perspectives of muslims regarding euthanasia. Active euthanasia is prohibited in Islam. This view is strongly supported by laws and ethical princiles in Islamic communites. However, administering analgesic agents that might shorten the patient's life, with the purpose of relieving the physical pain is accepted, because it is not aimed at killing. On the other hand, negative euthanasia is never accepted. However, withdrawing a futile treatment and allowing death to take its natural course for persons who are already died is acceptable. In this situation, the patient is already dead, and there is no use of keeping life supporting instruments. It is highly recommended for all health care professionals who are providing care for muslim patients to carefully consider the Islamic perspective regarding euthanasia.
\end{abstract}

Keywords: Euthanasia, Analysis, Concept, Islam, Perception, Law, Ethic

\footnotetext{
* ADDRESS FOR CORRESPONDENCE: Ahmad Hussien Rayan, Faculty of Nursing, Zarqa University, Jordan. E-mail address: ahmed rayan87@yahoo.com
} 
Rayan, A., H., Alzayyat A. \& Khalil, M., M. (2016). Euthanasia: Analysis for the Concept from Islamic Perception, Global Journal on Advances in Pure \& Applied Sciences. [Online]. 07, pp 175-182. Available from: www.propaas.eu

\section{Introduction}

Euthanasia is religiously, emotionally, and politically charged topic [16]. People's view of the permissibility of euthanasia is influenced by religious believes, ethics, and national laws for a specific society [19]. Euthanasia can be defined as as "a deliberate act, undertaken by a physician, to end the life of a person at his request in the name of compassion either passively or actively" [29]. Passive euthanasia is defined as "discontinuation of medical treatment in relation to a patient who is subjected to incurable disease when a doctor regards that further treatment only prolongs patient's suffering at time of dying" [35]. Active euthanasia is defined as "an act of behavior which consists of action in order to cause or hasten someone's death through, for example, delivery of lethal dose of drug or other deprivation of life" [35].

Recently, issues like terminating the life of patients who have incurable, painful, or distressing illness, and wheather euthanasia is acceptable legally, ethically, and by religion are highly debatable issues in health care systems [6]. Inghelbrecht, Bilsen, Mortier, and Deliens (2009) [14] reported that there is a broad support among nurses about euthanasia for terminally ill patients. However, both physicians and ethicists have reported repeatedly on the morally and emotionally challenging experience of euthanasia [5].

The concept of holism in health care, requires health care professionals to integrate spiritual aspects in their decision making while dealing with patients, especially in Islamic communities who consider Islam as a total system for living [24]. Nevertheless, few articles examined the ways in which the Islamic religion specifically contributes to shaping an individual's perceptions regarding euthanasia. Therfore, the purpose of this paper is to examine the Islami view for the concept of euthanasia and its permissiblility in Islam, while integrating different ethical and legal perspectives.

To examine the the concept of euthanasia and its permissiblility in Islam, it is important to integrate the ethical and legal perspectives which are important considerations in health care systems. Therefore, the major three criteria that will be discussed and integrated in this paper are ethical aspects, religious aspects, and legal aspects. These criteria have a major role in determining the permissibility of euthanasia [19].

\subsection{Ethical Perspective}

The permissibility of euthanasia is a serious ethical issue in bioethics [6]. Most people either strictly forbid it or firmly favor euthanasia. From an ethical view, arguments supporting euthanasia focus on dignity, autonomy, reduction of suffering, altruism, and fairness [12]. In addition, arguments concern about the emotional burden of end-of-life decision making for family members, and worry about the economic burden of terminal illness [13].

\section{Ethical Views Supports Euthanasia}

\subsection{Dignity}

The concept of "death with dignity" is a common concern among those who support active euthanasia. The idea is that prolonged death in a medical setting is unnatural and undignified [38]. In addition, people who support euthanasia believe that it allows a person to die with dignity instead of being kept hardly alive by artificial means [21]. This idea argues that people with terminal illness, receive drugs that might affect them to the point that they would be slipping into and out of consciousness besides tubes and various things stuck into their body, making them humiliated [33]. 
Rayan, A., H., Alzayyat A. \& Khalil, M., M. (2016). Euthanasia: Analysis for the Concept from Islamic Perception, Global Journal on Advances in Pure \& Applied Sciences. [Online]. 07, pp 175-182. Available from: www.propaas.eu

\subsection{Autonomy}

People who support euthanasia believe in giving primacy to the value of respecting individuals' rights to autonomy [6]. Moreover, advocates of euthanasia argue that terminating life at the request of an individual is moral because it is the individual's decision to make [2]. Some argues that if a competent person autonomously chooses to end his or her life or have someone else assist him or her in doing so, then it is autonomous choice that should be respected [6].

\subsection{Reduction of Suffering}

People who support euthanasia argue that it is inhumane to refuse a suffering patient's request to die [23]. Benedict, Caplan, and Page (2007) [4] reported that nurses who killed psychiatric patients at the state hospital of Meseritz-Obrawalde in the Nazi euthanasia program demonstrated a belief in the reduction of suffering as the most common cause for participating in killing those patients. Therefore, the reason why the patient asks for death is to eliminate suffering, which in the judgment of the patient, is an unbearable harm to himself [23]. Moreover, Smets (2011) [36] found that ninety percent of physicians accepted euthanasia for terminal patients who had extreme uncontrollable pain.

\subsection{Altruism}

Euthanasia is supported by utilitarian theory. This theory stated that when the resources are limited for health care, it is not appropriate to waste the resources to maintain the life of a terminally ill patient when those resources could be used to help other patients who may have better prognoses. Furthermore, it is unfair to the family members to deplete their savings in the process of care for their terminally ill relative, leaving them without resources important to the pursuit of their happiness [17].

\section{Ethical Views Against Euthanasia}

\subsection{Justice and Fairness}

Persons who euthanize others may not have the objectivity for their decision [8]. Therefore, terminating life is unethical in today's society because there are not enough protections that would allow for a just and fair practice of euthanasia [18]. In addition, people who are accepting euthanasia accepts that some persons (those of the disabled or sick) are worth less than others [8].

\subsection{Starting of Slippery Slope}

If active euthanasia was officially recognized, clients could be someway coerced to ask for euthanasia that opposed to their proper wishes [2]. In applying the slippery slope idea to euthanasia, opponents argue that if society officially allows active euthanasia for incurably patients who ask for it because of severe pain or suffering, less complicated cases will ultimately be accepted [7].

\subsection{Not to Harm}

Euthanasia is a break of one's duty as healer and comforter, and a violation of the long standing traditions of the nursing and medical communities not to kill our patients even when asked [28]. The primary moral objection to physician involvement in euthanasia argues that it violates the physician's ethical duty "do no harm" [8]. 
Rayan, A., H., Alzayyat A. \& Khalil, M., M. (2016). Euthanasia: Analysis for the Concept from Islamic Perception, Global Journal on Advances in Pure \& Applied Sciences. [Online]. 07, pp 175-182. Available from: www.propaas.eu

\section{Religous Perspective}

Religion has been considered an important factor in determining the degree to which a specific population accept the idea of euthanasia [30]. In general, the weaker religious belief is associated with a higher acceptance of euthanasia [9, 32]. However, some argue that some religious belives may support acceptance of euthanasia.

\subsection{Religious View Supports Euthanasia}

Some people defend that Muslim scholars are agree with negative euthanasia in certain circumstances. Dr. Muzzami Siddiqi, former president of the Islamic Society of North America, wrote: "If the patient is on life support, it may be permissible, with due consideration and care, to decide to switch off the life-support machine and let nature take its own time." [1]. On the other hand, administering analgesic agents that might shorten the patient's life, with the purpose of relieving the physical pain was reported to be accepted from Islam view [1].

The Islamic Code of Medical Ethics, issued by the First International Conference on Islamic Medicine held in Kuwait, in 1981, stated: " the doctor is well advised to realize his limit and not transgress it. If it is scientifically certain that life cannot be restored, then it is futile to diligently keep the patient in a vegetative state by heroic means or to preserve the patient by deep freezing or other artificial methods. It is the process of life that the doctor aims to maintain and not the process of dying" [26].

In addition, "At several meetings held in Mecca, Jeddah, and Amman, Muslim jurists of different schools ruled that once invasive treatment has been intensified to save the life of a patient, lifesaving equipment cannot be turned off unless the physicians are certain about the inevitability of death" [34].

However, in the instance of brain death, which is caused by irreversible damage to the brain, including loss of spontaneous respiration, the jurists ruled that "if three attending physicians attest to a totally damaged brain that results in an unresponsive coma, apnea, and absent cephalic reflexes, and if the patient can be kept alive only by a respirator, then the person is biologically dead, although legal death can be attested only when the breathing stops completely after the turning off of life-saving equipment" [34].

\section{Religious View Against Euthanasia}

According to Islam religion, the stronger and more widely accepted opinion is against euthanasia primarily because society feels that it is Allah's task to determine the time in which person will die, and we as human beings are in no position to behave as Allah and end someone's life [29]. Therefore, when humans take it upon themselves to shorten their lives or to have others to do it for them, they perform Allah's task and interfere with the divine plan. Allah says "Nor can a soul die except by Allah's leave, the term being fixed as by writing" (Qur'an 39:42) and "Allah takes away the souls upon their death; and of those who do not die during their sleep, those on whom He has passed the decree of death He keeps with Him and the rest He restores for a term ordained. Verily in this are signs for those who reflect" (Quran 3:145) [37].

In Islam, health-care providers must do everything possible to prevent premature death [29]. In the holly Qur'an Allah says "All you who believe, seek your help in patience and prayer; surely Allah is with the patient" (Qur'an 2:153-57). In addition, the profit Mohammad said: "No fatigue, nor disease, nor sorrow, nor sadness, nor hurt, nor distress befalls a Muslim, even if it were the prick he received from a thorn, but that Allah expiates some of his sins forthat." [20]. Theses texts indicate that Allah will reward those people who are suffering if they have patience, not if they killed themselves.

It is clear now that positive euthanasia is prohibited from Islamic view, Allah said: "If anyone kills a person unless it is for murder or spreading mischief in the land it would be as if he killed the whole 
people "(Qur'an 5:32) [1]. The physician must not take an active part in ending life of a patient, even if it is at his or her request, and even if the reason is severe deformity; a hopeless, incurable disease; or severe unbearable pain. However, the physician should urge his patient to keep patience and remind him of the reward of those who tolerate their suffering [1].

On euthanasia, Dr Zakir Naik said: "mercy killing was not permitted in Islam" (Bülow, 2008). However, if a patient has brain death and the family was incurring huge expenditure in keeping him alive with the support of machines and if there is no hope after removing the machines, the family could remove the machines [1]. This does not agree with euthanasia, but emphasize that lifesustaining instrument such as ventilators, can be removed from the person who is biologically dead.

\section{Legal Perspective}

\subsection{Legal View Supports Euthanasia}

The liberalization of issues in connection with euthanasia is active in some countries, by going down to the legalization in the Netherlands, Oregon, and Columbia [10]. Dutch law, for example, describe euthanasia as "medical active intervention in the purpose of interrupting the patient's life, at his request" [10]. To facilitate application of this law, it is required the existence of the client's consent, otherwise this practice is considered a criminal act [25]. Similarly, in 1994, in Oregon euthanasia was officilay recognized and The Oregon Death with Dignity Act law was established which stipulates and authorizes the procedures concerning the euthanasia [27]. In addition, Columbia was the first country on the American continent that legally recognized euthanasia [10]. This may encourage other countries to accept euthanasia.

\subsection{Legal View against Euthanasia}

Threre are few countries in the world where euthanasia can be practiced legally in a medical context and under well defined circumstances. For example, physicians in Belgium, may under certain conditions, administer life ending drugs at the explicit request of a patient, and under legal protection [36]. However, in Arab and Muslim countries, any person performing an euthanasia is subject to liability and/ or imprisonment [3].

In the international law there is almost worldwide prohibition of active euthanasia and health care providers participation in such activity [35]. Human life is guarded by several of legal regulations. For instance, article 6 of the International Covenant on Civil and Political Rights stated that "Every human being has the inherent right to life. This right shall be protected by law. No one shall be arbitrarily deprived of his life" [15]. Likewise, article 2 of the European Convention on Human Rights indicated that "Every human being has the inherent right to life. This right shall be protected by law. No one shall be arbitrarily deprived of his life" [31].

Furthermore, there are several legal standpoints against euthanasia in the Islamic and Arab countries. For example, the law in United Arab Emirates prohibits the medical professional from ending a patient's life whatever was the reason. In addition, the law considers this practice unlawful regardless of requests and consent of the patient or the patient's guardian [3]. Therefore, violation is punishable by a prison sentence of not less than 10 years.

\section{Discussion}

Clearly, the ethical position toward euthanasia is complex. The major ethical princibles supporting euthanasia include respect for dignity and autonomy, reduction of suffering, and altruism. The major ethical principles against euthanasia include not to harm, starting of slippery slope, and justice and fairness. These choices are in conflict and both sides seem justifiable. Actually, the major ethical 
principles that supported euthanasia are not well justified. Regarding the dignity of patient, people who support euthanasia believe that it allows a person to maintain his or her dignity. However, euthanasia does violence to the dignity of the patient because human dignity comes from seeking our ends; one of our ends is survival, and euthanasia goes against that end which undermines one's dignity [11]. In addition, terminating life violates the basic human right not to be killed [22]. Accepting euthanasia would actually undermine people's autonomy. People who ask for euthanasia may not actually want it, but just look for a mean to eliminate their suffering. They may have a distressing symptom needs palliation. They may also have deression which is common in terminally ill patients and leads to suicidal thoughts. In addition, vulnerable people such as the elderly, lonely, sick or distressed will feel pressure to request euthanasia because they often feel a burden on relatives, carers and a society. The issue of "reduction of suffering" is also not clear; It is unknown what doctors consider 'unbearable suffering' and for what kind of suffering they are willing to grant euthanasia request [5]. In addition, there is no specific kind or level of suffering that is determined to apply euthanasia. This will increase subjectivity in decision making. On the other hand, additional suffering can occur to relatives and friends after the loss of loved one by euthanasia. The principle of altruism is not justified. It sounds inhumane to measure a person's life in dollars. However, if the resources are limited and there are other patients who are expected to have good prognosis using less resources, they should have the priority to get use of the few resources available. In this situation, euthanasia is acceptable because of lack of resources, not because it is a good choice.

From Islamic perspective, some defend that Muslim scholars are agree with euthanasia, this is not accurate. As identified in the previous discussed literature (Bülow, 2008; 29, 37] positive euthanasia is prohibited from Islamic view. Muslim scholars who talked about permissibility of euthanasia do not agree with active euthanasia. Moreover, they emphasize that life-sustaining instrument such as ventilators, can be removed from the person who is biologically dead. In this situation, physicians do not kill a patient by omitting treatment, but rather the disease takes the patient's life.

Therefore, assisted suicide and positive euthanasia are not acceptable in Islam, and the physician should not take an active part in terminating the life of any patient, even if it is upon patient's request. In the case of severe deformity; hopeless, incurable disease; or severe unbearable pain that cannot be alleviated by the usual painkillers, the physician should remind his patient of the reward of those who tolerate their suffering. Allah said: "If anyone kills a person unless it is for murder or spreading mischief in the land it would be as if he killed the whole people (Qur'an 5:32) " [1].

However, there are two important points related to patients' dignity during dying process. In the instance of brain death, which is caused by irreversible damage to the brain, the person is biologically dead, withdrawing a futile treatment and allowing death to take its natural course, especially for the already-dead patient is really accepted. In this situation, physicians do not kill a patient by omitting treatment, but rather the disease takes the patient's life. Patients have a right to a "death with dignity" and allowing a dignified death to occur naturally is a moral act $[18,26]$.

In addition, administering analgesic agents that might shorten the patient's life, with the purpose of relieving the physical pain is also accepted in Islam [1]. In this instance, death is recorded as caused by the person's underlying disease rather than the intentional act of turning off the respirator [1]. Moreover, refusal to recognize the inevitability and naturalness of death and the biological death leads to more aggressive life-saving interventions, which will never retain the patient to the life. However, to withhold specific interventions at the most critical time results in deliberate avoidance of responsibility in administering the right treatment to save a patient's life is not accepted (Bülow et al., 2008).

While there are some western contries allow euthanasia, the law in Islamic and Arab countries is against it. This will protect the Islamic societies from the negative consequences of legalizing euthanasia which may lead to providing poor care for the terminally ill patients and undermining the commitment of doctors and nurses to saving lives. In addition, allowing euthanasia will discourage the 
search for new cures and treatments for the terminally ill, and exposes vulnerable people to pressure to end their lives [7].

Therefore, if euthanasia becomes legalized, doctors may have too much power and start killing their patients. If this occurred, we would open the doors to have doctors murdering their innocent patients. On the other hand, if a patient is miss diagnosed with a disease, and euthanasia was legalized, the patient may kill himself or herself because of it and then it is discovered that he or she doesn't have that disease at all, it would be a terrible and the person along with their family would have suffered a great loss. To prevent these problems, euthanasia shouldn't be legalized or controlled by a human's power.

\section{Conclusion}

The general Islamic view is that euthanasia is not acceptable. This view is strongly supported by laws that govern the Islamic communites. In addition, it is supported by different ethical principles. However, in some instances, the passive assistance in allowing a terminally ill patient to die such as withdrawing a futile treatment and allowing death to take its natural course, especially for the already-dead patient and administering analgesic agents that might shorten the patient's life, with the purpose of relieving the physical pain are acceptable from Islamic view. It is highly recommended for all health care professionals who are providing care for a muslim patient to take into consideration the Islamic perspective regarding euthanasia and other end of life issues.

\section{References}

[1] Aramesh, K., \& Shadi, H. (2007). Euthanasia: an. Islamic ethical perspective. Iran J Allergy Asthma Immunol, 6 (5) 35-38.

[2] Barbuzzi, M. (2014). Who Owns the Right to Die? An Argument about the Legal Status of Euthanasia and Assisted Suicide in Canada. Penn Bioethics Journal, 10(1).

[3] Benomran, F. (2010). Medical responsibility in the United Arab Emirates. Journal of Forensic and Legal Medicine, 17, 188-193.

[4] Benedict, S., Caplan, A., \& Page, T. (2007). Duty and 'Euthanasia': the Nurses of Meseritz- Obrawalde. Nursing Ethics 14 (6), 781- 794.

[5] Boera, M., Dröesa, R., Jonkerb, C., Eefstinga, J., \& Hertogh, C. (2010). Advance directives for euthanasia in dementia: Do law-based opportunities lead to more euthanasia? Health Policy, 98, 256-262

[6] Boudreau, J. D., \& Somerville, M. (2014). euthanasia and assisted suicide: a physician's and ethicist's perspectives. International Journal of Nanomedicine, 9, 1883-1889.

[7] Collier, C., \& Haliburton, R. F. C. (2011). Bioethics in Canada: A Philosophical Introduction. Canadian Scholars' Press.

[8] Cundiff, D. (2012). Euthanasia is not the answer: A hospice physician's view. Springer Science \& Business Media.

[9] Danyliv, A., \& O'Neill, C. (2014). Attitudes towards legalising physician provided euthanasia in Britain: The role of religion over time. Social Science \& Medicine.

[10] Diaconescu, A. M. (2012). Euthanasia. Contemporary Readings in Law and Social Justice, 4(2), 2012, 474483.

[11] Dieterle, J. M. (2007). Physician assisted suicide: a new look at the arguments. Bioethics, 21(3), 127-139.

[12] Eliott, J.A., \& Olver, I.N. (2008). Dying cancer patients talk about euthanasia. Social Science \& Medicine, 67, 647-656.

[13] Givens, J., \& Mitchell, S. (2009). Concerns About End-of-Life Care and Support for Euthanasia. Journal of Pain and Symptom Management, 38 (2). 
Rayan, A., H., Alzayyat A. \& Khalil, M., M. (2016). Euthanasia: Analysis for the Concept from Islamic Perception, Global Journal on Advances in Pure \& Applied Sciences. [Online]. 07, pp 175-182. Available from: www.propaas.eu

[14] Inghelbrecht, E., Bilsen, J., Mortier, F., \& Deliens, L. (2009). Attitudes of nurses towards euthanasia and towards their role in euthanasia: A nationwide study in Flanders, Belgium. International Journal of Nursing Studies, 46, 1209-1218.

[15] Hoag, R. W. (2011). International Covenant on Civil and Political Rights. InEncyclopedia of Global Justice (pp. 544-545). Springer Netherlands.

[16] Holm, S. (2010). Euthanasia: agreeing to disagree?. Medicine, Health Care and Philosophy, 13(4), 399-402.

[17] Ho, Z. J. M., Krishna, L. K. R., \& Yee, C. P. A. (2010). Chinese familial tradition and Western influence: a case study in Singapore on decision making at the end of life.Journal of pain and symptom management, 40(6), 932-937.

[18] Kibria, G. (2014). Ethical Issues In Medical Practice. Journal of Bangladesh College of Physicians and Surgeons, 31(3), 120-121

[19] Kon, A. (2009). Neonatal Euthanasia. Semin Perinatol, 33, 377-383.

[20] Kristiansen, M., \& Sheikh, A. (2012). Understanding faith considerations when caring for bereaved Muslims. Journal of the Royal Society of Medicine, 105(12), 513-517.

[21] Martin, B. (2013). In search of gentle death: the fight for your right to die with dignity. Prometheus, 31(1), 75-77.

[22] Mason, K., Laurie, G., \& Smith, A. M. (2013). Mason and McCall Smith's Law and Medical Ethics. Oxford University Press.

[23] Materstvedt, L. J. (2012). Intention, procedure, outcome and personhood in palliative sedation and euthanasia. BMJ supportive \& palliative care, 2(1), 9-11.

[24] Narayanasamy, A., \& Andrews, A. (2000). Cultural impact of Islam on the future directions of nurse education. Nurse Education Today, 20, 57-64.

[25] Onwuteaka-Philipsen, B. D., Brinkman-Stoppelenburg, A., Penning, C., de Jong-Krul, G. J., van Delden, J. J., \& van der Heide, A. (2012). Trends in end-of-life practices before and after the enactment of the euthanasia law in the Netherlands from 1990 to 2010: a repeated cross-sectional survey. The lancet, 380(9845), 908-915.

[26] Padela, A. I. (2007). Islamic medical ethics: a primer. Bioethics, 21(3), 169-178.

[27] Purvis, T. E. (2012). debating death: religion, Politics, and the oregon death With dignity Act. The Yale journal of biology and medicine, 85(2), 271.

[28] Quaghebeur, T., de Casterlé, B. D., \& Gastmans, C. (2009). Nursing and euthanasia: a review of argumentbased ethics literature. Nursing ethics, 16(4), 466-486.

[29] Rather, M. Y., Rani, A., \& Fauzi, M. (2012). Euthanasia and physician-assisted suicide: a review from Islamic point of view. International Medical Journal Malaysia, 11(1), 63-68.

[30] Rathor, M. Y., Rani, M. F. A., Shahar, M. A., Jamalludin, A. R., Abdullah, S. T. B. C., Omar, A. M. B., \& Shah, A. S. B. M. (2014). Attitudes toward euthanasia and related issues among physicians and patients in a multi-cultural society of Malaysia. Journal of family medicine and primary care, 3(3), 230.

[31] Rainey, B., Wicks, E., \& Ovey, C. (2014). Jacobs, White and Ovey: the European convention on human rights. Oxford University Press.

[32] Romain, M., \& Sprung, C. L. (2014). End-of-life practices in the intensive care unit: the importance of geography, religion, religious affiliation, and culture. Rambam Maimonides medical journal, 5(1).

[33] Ruiz, Á. (2008). Right to die with dignity?. Biomédica, 28(2), 191-194.

[34] Sachedina, A. (2005). End of life: Islamic view. International Journal for the Psychology of Religion, 13 (2), 111-122.

[35] Śliwka, M., \& Gałęska-Śliwka, A. (2011). Regulating end of life decisions in Poland: legal dilemmas. Advances in Palliative Medicine, 10(2), 49-56.

[36] Smets, T., Cohen, J., Bilsen, J., Wesemael, Y., Rurup, M.L., \& Deliens, L. (2011). Attitudes and Experiences of Belgian Physicians Regarding Euthanasia Practice and the Euthanasia Law. Journal of Pain and Symptom Management, 41(3), 580-592.

[37] Taqi, A. (2012). Euthanasia: is it really a bad idea. Anaesthesia, Pain \& Intensive Care, 16(3), 226-229.

[38] Yousuf, R. M., \& Mohammad Fauzi, A. R. (2012). Euthanasia and Physician-Assisted Suicide: A Review from Islamic Point of View. International Medical Journal Malaysia, 11(1). 